\title{
Non-STEM students' learning difficulties and coping strategies in general chemistry under an engineering course program
}

Capanzana, Carmela

Philippine Normal University, Philippines (capanzana.co@pnu.edu.ph)

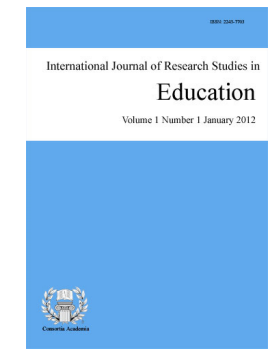

ISSN: $2243-7703$ Online ISSN: 2243-7711

\section{Abstract}

The study explored and described the non-STEM students' stressful learning difficulties in general chemistry and their coping strategies to address them. A descriptive multiple case study design is revised as descriptive cross-sectional survey to gather students' coping strategies in general chemistry. The sample of the study consisted of one intact section of non-STEM students $(n=21)$ enrolled in an Engineering course program, Bachelor of Science in Electrical Engineering under a state university's Bridge Program in the Philippines. The quantitative data were gathered using the Ways of Coping Checklist as the instrument while focused group discussion and face-to-face interview were employed to gather qualitative data. Descriptive statistics such as frequency, percentage, weighted arithmetic mean and standard deviation were used to analyze the quantitative data while thematic analysis was used to analyze the qualitative data and confirm the quantitative analyses. Results showed that among the eight coping strategies in the research instrument, accepting responsibility got the highest weighted mean of 2.83 with an SD of 0.98 followed by positive reappraisal with a weighted mean and SD of 2.10 and 0.89 , respectively. These results imply that these strategies were more frequently used by students compared to other strategies. These results were confirmed by the emerging themes derived from the thematic analysis were students identified these two coping strategies they used more frequent that others. It is recommended that orientation on stress and coping strategies and appropriate intervention be employed to address students' stressful encounter in general chemistry.

Keywords: learning difficulties; coping strategies; general chemistry; non-STEM students; engineering course program 


\section{Non-STEM students' learning difficulties and coping strategies in general chemistry under an engineering course program}

\section{Introduction}

In 2017, the Philippine government through its Department of Education (DepEd) produced its first batch of senior high school graduates after adopting the $\mathrm{K}$ to 12 Basic Education Curriculum. Based on the existing guidelines, senior high school graduates who have taken the Technological-Vocational and Livelihood (TVL) track may no longer pursue a four-year course in state universities and colleges (SUCs). On the other hand, other graduates need to take and pass the college entrance examinations to get into their chosen course which is aligned to the track they have taken in senior high school. However, this was not the case for those senior high school graduates who passed the college entrance examinations and wanted to pursue courses which are not aligned with their track. In order to open opportunities for them, through the government's Commission on Higher Education (CHED), higher education institutions (HEIs) were allowed to offer Bridge Programs for senior high school graduates who chose to enroll on courses which are not aligned with their track. This is in accordance with the CHED Memorandum Order no. 105, s. 2017 which included the policies on the senior high school graduates' admission to the HEIs specifically the policy stating that Grade 12 students who will be graduating starting from Academic Year 2017-2018 are entitled to pursue college regardless of the track taken in senior high school.

Accordingly, a Philippine state university in Quezon province, started to offer the Bridge Program for their first-year college students during the first semester in 2018. For instance, the participants of this study were non-STEM students who were pursuing an Engineering course, B.S in Electrical Engineering. Under the said Bridge Program, they were required to take and pass subjects which are prerequisites of major subjects they would take later in their course. One of these subjects is General Chemistry which is being taken by STEM students in senior high school. Non-STEM students felt threatened to fail General Chemistry since they did not take it during senior high school and failing this subject would hinder them to get into the Engineering program.

Thus, major events happening in a person's life are perceived as traumatic or critical and not normal. Specifically, for adolescents, the said events may involve death of a loved one, parental divorce or transferring to other schools. Despite having lesser occurrence than daily stressful experiences, major life events are perceived more negatively, more challenging and more threatening to one's coping mechanisms (Williams \& Mc Gillicuddy-De Lisi, 2000). This can be seen in the study conducted by Davis and Compas (1986) among adolescents which viewed major life events as undesirable and difficult stressors. In view of these, the experience of being under a Bridge Program to pursue an Engineering course can be considered as a major life event to non-STEM students. The said event may generate challenging, threatening and undesirable experiences such as encountering learning difficulties in their prerequisite subjects like general chemistry, failing the said subject and being not able to pursue their Engineering course. Sirhan (2000) noted that many students found Chemistry difficult. In this regard, the said difficulties may cause stress to non-STEM students. As new college students, the stress they are experiencing could occur regularly due to their transition from the high school level to college level (Coelho et al., 1963; Dressler, 1991; Dyson \& Renk, 2006; McClure, 2007). In order to deal with the said stress, individuals apply coping mechanisms which could affect how they will react with the stress they are experiencing (Carver \& Scheier, 1994; Carver et al., 1989).

Coping is the person's dynamic cognitive and behavioral efforts towards managing specific life's demands which exceed his abilities to address them. As a process-oriented concept, it focuses on the person's thoughts and actions taken during the stress encounter. Further, it is contextual since it considers the person and situation in shaping the coping efforts. Lastly, it has no presumptions on the ability of the person to succeed in managing the stress (Folkman \& Lazarus, 1980; Folkman \& Lazarus, 1985; Folkman et al., 1986; Lazarus, 1993; Lazarus \& 
Folkman, 1984).

In view of the above concerns, the study explored the non-STEM students' stressful learning difficulties and their coping strategies to address them. Specifically, it sought to investigate on the following research questions:

$>\quad$ What were the learning difficulties encountered by non-STEM students in general chemistry?

$>$ How do non-STEM students coped with the stressful learning difficulties they encountered in general chemistry?

\subsection{Framework of the study}

In this study, Lazarus' cognitive phenomenological theory of stress was used as the framework for achieving the research's objectives. The said theory includes three types of stress such as challenge, threat and harm-loss. Challenge involves using mastery to overcome hindrances and thus gain something. On the other hand, threat involves anticipation of potential harm-loss which is then defined as the actual loss of something. According to the theory, a person encountering a stress takes primary assessment to weigh the situation and then proceeds with secondary assessment on his/her coping resources and look on alternatives to manage the situation. Upon seeing whether coping efforts affect or not the situation, new assessments and coping efforts are applied (Folkman \& Lazarus, 1980). In order to assess how people manage stressful experiences, the Ways of Coping Scale was developed. The said instrument are consisted of eight coping subscales such as confrontive coping, self-control, distancing, seeking social support, escape-avoidance, accepting responsibility, positive reappraisal and planful problem solving.

First, confrontive coping, pertains to the use of aggressive efforts of a person to change the situation, show a degree of hostility and taking risk. Second, distancing describes person's effort to detach oneself or creating a positive perspective of the situation. Third, self-control refers to efforts to regulate one's emotions. Fourth, seeking social support works towards seeking support from others in terms of getting information, getting help in solving a concrete problem and getting sympathy from others. Fifth, accepting responsibility means acknowledging one's role in a problem and making right actions towards it. Sixth, escape-avoidance pertains to wishful thinking and behavioral efforts to escape or avoid the situation. Lastly, planful problem solving describes efforts focused on changing the situation to solve the problem by taking a plan of action using different solutions to the problem (Folkman et al., 1986).

\section{Methodology}

\subsection{Research design}

The study employed descriptive cross-sectional survey to explore non-STEM students' learning difficulties and their coping strategies in general chemistry.

\subsection{Participants and locale}

Twenty-one (21) first year college students enrolled in B.S. Electrical Engineering participated in this study. They were the non-STEM students who were under the Bridge Program of a Philippine state university in Quezon province.

\subsection{Instrument}

In this study, a modified version of a survey based on the Ways of Coping Checklist was given to the participants. The said survey is consisted of 66 items representing the eight coping processes as discussed under the framework of the study. These include confrontative coping, distancing, self-controlling, seeking social 
support, accepting responsibility, escape-avoidance, planful problem solving and positive reappraisal. Each item presented in the survey has a 4-point Likert-type scale showing how frequent the said item is used. These scales are 0 meaning not used; 1 for used somewhat; 2 for used quite a bit and 3 for used a great deal. In terms of reliability, the study's results which used the said instrument generated Cronbach alphas ranging from .69 to .79 (Folkman \& Lazarus, 1988) which were acceptable.

\subsection{Data collection}

After having sought the approval of the concerned higher education institution and consent of the participants and their general chemistry teacher, individual copies of the Ways of Coping Checklist as the research instrument were distributed to the participants to determine their coping strategies in general chemistry. As a means of triangulation, twelve (12) students were randomly selected to engage in focused group discussion and a face-to-face interview was conducted with their general chemistry teacher to gather qualitative data and confirm the quantitative results gathered using the instrument.

\subsection{Data analysis}

Descriptive statistics such as frequency, percentage, weighted arithmetic mean and standard deviation were used to analyze the quantitative data while thematic analysis was used to confirm the quantitative analyses of the students' coping strategies in general chemistry. In the thematic analysis, this study used a coding scheme in which codes were identified based on the students' responses and their general chemistry teacher's responses. These codes were then categorized and emerging themes were established based on the description of each coping strategy.

\subsection{Ethical considerations}

Prior to the conduct of survey and interviews, informed consent forms were secured from the participants. The data gathered from them were treated with high anonymity and confidentiality. In order to ensure scientific honesty, appropriate citations of original authors were included.

\section{Results and discussion}

\section{What are the learning difficulties students encountered in general chemistry?}

The general chemistry teacher was asked about the learning difficulties that students' encountered in general chemistry. The students found problem solving involving volume calculations and stoichiometry difficult.

"In the problem solving, they found the calculation in volume difficult. One of my best students in the class even told me that she has to get a copy of a chemistry e-book from his classmate studying in another university to find the correct solution to the problem. They had difficulty in stoichiometry, we started with conversion, then naming and writing chemical formulas of compounds, after that periodic table, then lastly was stoichiometry until combustion analysis." General Chemistry Teacher (date of interview: November 26, 2018)

Although students were not directly asked about their learning difficulties, some of their responses indicated the learning difficulties they encountered in general chemistry. The students found the chemistry lessons involving calculations such as stoichiometry difficult.

\footnotetext{
"In calculations, we asked other first year STEM students to teach us the solution if we did not know how to do it." - Student A (date of interview: November 26, 2018)

"I go to Professor X (another general chemistry teacher) and Engr. Y( teacher in Chemistry for Engineering from which general chemistry is a prerequisite) and request to teach me how to do
} 
Non-STEM students' learning difficulties and coping strategies in general chemistry under an engineering course

the calculations in stoichiometry.” - Student C (date of interview: November 26, 2018)

"I watched videos from Youtube which show how the calculations can be done. I found it easy for

me to watch the videos." - Student B (date of interview: November 26, 2018)

Based on the responses of students in the focused-group discussion and their general chemistry teacher in the face-to-face interview, most of the students found the topics involving problem solving which require long process of calculations difficult to learn such as their lessons involving volume and in stoichiometry.

\section{How non-STEM students cope with their learning difficulties in general chemistry?}

Table 1 and 2 present the results of analyses using descriptive statistics using frequency, percentage, weighted arithmetic mean and standard deviation on coping strategies used by students to address their learning difficulties in general chemistry based on their responses in Ways of Coping Checklist.

\section{Table 1}

Frequency and percentage coping strategy scores of non-STEM students

\begin{tabular}{|c|c|c|c|c|c|c|c|c|c|c|}
\hline \multirow{2}{*}{ Coping Strategy } & \multirow{2}{*}{$\begin{array}{l}\text { No. of } \\
\text { Items }\end{array}$} & \multirow{2}{*}{$\begin{array}{c}\text { Total } \\
\text { Frequency }\end{array}$} & \multicolumn{4}{|c|}{ Frequency } & \multicolumn{4}{|c|}{ Percentage (\%) } \\
\hline & & & 0 & 1 & 2 & 3 & 0 & 1 & 2 & 3 \\
\hline 1. Confrontive coping & 6 & 126 & 26 & 41 & 38 & 21 & 21 & 33 & 30 & 17 \\
\hline 2. Distancing & 6 & 126 & 20 & 43 & 32 & 31 & 16 & 34 & 25 & 25 \\
\hline 3. Self-controlling & 6 & 126 & 20 & 39 & 41 & 26 & 16 & 31 & 33 & 21 \\
\hline 4. Seeking social support & 6 & 126 & 19 & 25 & 42 & 40 & 15 & 20 & 33 & 32 \\
\hline 5. Accepting responsibility & 4 & 84 & 8 & 10 & 27 & 39 & 10 & 12 & 32 & 46 \\
\hline 6. Escape-avoidance & 8 & 168 & 38 & 48 & 50 & 32 & 23 & 29 & 30 & 19 \\
\hline 7. Planful problem solving & 6 & 126 & 5 & 26 & 69 & 26 & 4 & 21 & 55 & 21 \\
\hline 8. Positive reappraisal & 7 & 147 & 9 & 26 & 55 & 57 & 7 & 19 & 40 & 41 \\
\hline
\end{tabular}

Note. ${ }^{\mathrm{a}} \mathrm{N}=21 .{ }^{\mathrm{b}}$ The numbers $0,1,2$ and 3 found under the columns frequency and percentage represent the 4-point Likert Scale : 0 - not used; 1 - used somewhat; 2 - used quite a bit and 3 - used a great deal used in Ways of Coping Checklist (Folkman \& Lazarus, 1988).

Table 1 shows the frequency and percentage of students' scores on the research instrument used which contains eight (8) coping strategies and each strategy has a corresponding number of items. In order to get the total frequency for each strategy, the number of items for each strategy was multiplied to the number of participants (sample, $N=21$ ). Based on the frequencies and percentage values for the first strategy, confrontive coping, Likert scale 1 denoting "used somewhat" got the highest values of 41 out of 126 constituting $33 \%$. In the second strategy, distancing, scale 1 again got the highest frequency and percentage which are 43 out of 126 and $34 \%$, respectively. However, on the third strategy, self-controlling, scale 2 denoting "used quite a bit" got the highest frequency and percentage of 41 and 33\%, respectively. Similarly, in the fourth strategy, scale 2 also got the highest values of 42 and 33\%. Furthermore, it is interesting to note that in the fifth strategy, accepting responsibility, scale 3 denoting "used a great deal" got the highest values of 39 and $46 \%$. On the sixth strategy and seventh strategy, scale 2 got the highest values of 50 and 30\% and 69 and 55\%, respectively. On the last strategy, scale 3 got the highest values of 57 and $41 \%$. Overall, these results imply that there are differences on how frequent did students use each strategy in addressing their learning difficulties in general chemistry.

Moreover, comparing the frequency and percentage values obtained from each strategy, it can be observed that two from the eight coping strategies, accepting responsibility (fifth) and positive reappraisal (eighth), showed the highest frequencies and percentages for scale 3 which denotes "used a great deal" which imply that most of the students used these two strategies more frequently compared to other strategies. However, the highest values for scale 1 were obtained for the first and second strategies which are confrontive coping and distancing implying that these strategies were used seldom by the students compared to other strategies. Furthermore, third, fourth, sixth and seventh strategies got the highest values in scale 2 implying that these strategies were used quite a bit by students compared to other strategies.

Table 2 presents the weighted mean and SD of students' strategy scores in the research instrument. It can be 
observed that the fifth strategy got the highest weighted mean of 2.83 with an SD of 0.98 . The next in rank is the eight strategies which is the positive reappraisal with a weighted mean and SD of 2.10 and 0.89 , respectively. These results imply that these strategies were more frequently used by students compared to other strategies. These also confirmed the results presented in Table 1. These results can be supported by the study of Williams and Mc Gillicuddy-De Lisi (2000) indicating that older adolescents used the coping strategies which include accepting responsibility, planful problem solving, seeking social support, self-controlling and positive reappraisal more often compared to young adolescents. Furthermore, according to the study of Folkman et al. (1986), accepting responsibility and positive reappraisal were also used in changing the situation in stressful encounters. "Criticized or lectured myself", "I made a promise to myself that things would be different next time", and "realized I brought the problem on myself", are the items in the Ways of Coping Checklist which describe accepting responsibility.

Table 2

Weighted mean and SD coping strategy scores of non-STEM students

\begin{tabular}{lcc}
\hline \multicolumn{1}{c}{ Coping Strategy } & Weighted Mean & SD \\
\hline 1. Confrontive coping & 1.43 & 1.00 \\
2. Distancing & 1.59 & 1.03 \\
3. Self-controlling & 1.58 & 0.99 \\
4. Seeking social support & 1.82 & 1.05 \\
5. Accepting responsibility & 2.83 & 0.98 \\
6. Escape-avoidance & 1.45 & 1.04 \\
7. Planful problem solving & 1.92 & 0.75 \\
8. Positive reappraisal & 2.10 & 0.89 \\
\hline
\end{tabular}

On the other hand, the lowest values were obtained in the first and second strategy, confrontive coping and distancing, implying that these strategies were not frequently used by students and also confirming the results in table 1. According to Lazarus and Folkman (1988), the coping strategy confrontive coping was often associated with younger group's worsened emotional conditions. On the other hand, the coping strategy distancing could lead to undesirable result when the person used it instead of addressing the problem (Folkman et al, 1986).

In addition to the quantitative results obtained from students' responses on the research instrument, qualitative results were also obtained from focused-group discussion with the students and face-to-face interview with their general chemistry teacher. Consequently, emerging themes were obtained through thematic analysis on non-STEM students' coping strategies in general chemistry.

\section{Table 3}

Emerging themes on non-STEM students' coping strategies in general chemistry

\begin{tabular}{|c|c|c|c|}
\hline $\begin{array}{c}\text { Codes } \\
\text { (Students) }\end{array}$ & $\begin{array}{l}\text { Codes } \\
\text { (Teacher) }\end{array}$ & Category & Emerging Theme \\
\hline $\begin{array}{l}\text { Asking the teacher on the } \\
\text { calculations which are difficult } \\
\text { to understand }\end{array}$ & $\begin{array}{l}\text { A student arguing to check } \\
\text { and fix the teacher's given } \\
\text { solution to a problem which } \\
\text { the student believed to be } \\
\text { wrong }\end{array}$ & $\begin{array}{l}\text { Asking on things that are } \\
\text { difficult to understand } \\
\text { Demanding to check and } \\
\text { fix things for them }\end{array}$ & Confrontive coping \\
\hline $\begin{array}{l}\text { Asking STEM students to } \\
\text { teach how to do the } \\
\text { calculations } \\
\text { Seeking other professors who } \\
\text { are knowledgeable about the } \\
\text { subject and request them to } \\
\text { teach how to do the } \\
\text { calculations in stoichiometry }\end{array}$ & $\begin{array}{l}\text { Students always asking on the } \\
\text { things they did not } \\
\text { understand especially on } \\
\text { calculations } \\
\text { A student referring to another } \\
\text { reference book to find the } \\
\text { correct solution to a problem }\end{array}$ & $\begin{array}{l}\text { Seeking the assistance of } \\
\text { others } \\
\text { Consulting with experts in } \\
\text { the subject } \\
\text { Referring to other } \\
\text { references }\end{array}$ & Seeking of social support \\
\hline
\end{tabular}


Students asking STEM

students and other professors

for the solutions to the

problems.

$\begin{array}{llll}\begin{array}{l}\text { Blaming oneself in failing the } \\ \text { exam. }\end{array} & \begin{array}{l}\text { A student telling oneself that } \\ \text { s/he not satisfied with the } \\ \text { way s/he reviewed for the } \\ \text { exam }\end{array} & \begin{array}{l}\text { Self-blaming } \\ \text { Setting self-expectation }\end{array} & \text { Accepting responsibility } \\ \begin{array}{l}\text { Going out and drinking with } \\ \text { friends after the final exam }\end{array} & \begin{array}{l}\text { Students sharing about } \\ \text { getting some sleep or } \\ \text { celebrating with their } \\ \text { classmates after the exam. }\end{array} & \text { Self-rewarding } \\ \begin{array}{l}\text { Getting some sleep after the } \\ \text { exam }\end{array} & \begin{array}{l}\text { Use of escape-avoidance } \\ \begin{array}{l}\text { Watching YouTube videos to } \\ \text { understand how to do the } \\ \text { calculations }\end{array}\end{array} \begin{array}{l}\text { Students using different ways } \\ \text { of solving the problems }\end{array} & \begin{array}{l}\text { Using different study } \\ \text { strategies }\end{array} & \text { Planful problem-solving } \\ \begin{array}{l}\text { Reviewing the night before the } \\ \text { exam }\end{array} & \begin{array}{l}\text { A student using varied } \\ \text { references on the subject. }\end{array} & \\ \begin{array}{l}\text { Writing the formulas in small } \\ \text { sheets of paper and pasting } \\ \text { them on the wall when } \\ \text { reviewing for the exam }\end{array} & \begin{array}{l}\text { Students always writing the } \\ \text { formulas }\end{array} & \end{array}$

Table 3 presents the emerging themes based on the responses of students and their general chemistry teacher on the students' use of coping strategies to address their learning difficulties in general chemistry. It can be observed that students have used coping strategies such as confrontive coping, seeking social support, accepting responsibility, escape-avoidance and planful problem solving which are also included in the Ways of Coping Checklist used in this study as the research instrument. These imply that students resorted to these coping strategies to address their learning difficulties in general chemistry in order to pass the said subject. Furthermore, these qualitative results confirmed the quantitative results already presented above.

\subsection{Implications of the study}

The similar results on the students' learning difficulties in general chemistry provide significant implications on the necessary knowledge and skills that non-STEM students must gain specifically mathematics concepts and problem solving skills. Since these students did not have any prior knowledge on Chemistry in their senior high school, they found understanding stoichiometry and solving problems involving it difficult. These difficulties can be addressed through the teacher's careful lesson planning and conduct of effective instructional strategies and necessary interventions to facilitate students' learning.

On the other hand, the varied results on the students' use of coping strategies implied that there could be contributing factors which may have influenced how students used these coping strategies such as personal characteristics like age, gender and educational background. It is also noteworthy that the use of coping strategies has been shown to vary with different individual characteristics. In general, it has been documented that men are more likely to use problem-focused coping strategies, whereas women are more likely to use emotion-focused coping strategies (Lawrence et al., 2006; Lazarus \& Folkman, 1984; Lo, 2002; Murray-Harvey et al., 2000; Shaikh et al., 2004). Furthermore, several findings suggest that types of coping strategies used by adolescents do change with age. Younger adolescents were reported that they dealt with stress by working more and distracting themselves from the problem, whereas older adolescents used tension reduction techniques more often than younger adolescents (Frydenberg \& Lewis, 1993; Murray-Harvey et al., 2000). 
Furthermore, the use of different coping strategies among students imply the different degrees of stress they felt while studying general chemistry specifically the learning difficulties they encountered. Consequently, the frequent use of coping strategies such as accepting responsibility and positive reappraisal implied that students were already responsible of their learning indicated by accepting responsibility. Also, these indicated that they possessed a positive attitude towards general chemistry manifested by their use of positive reappraisal despite of the different degrees of stress they encountered in the said subject. On the other hand, confrontive coping and escape-avoidance implied that students elicited negative attitude towards the subject. These also provide implications on the teacher-learning process specifically the application of differentiated instruction in order to address the students' individual differences such as their coping strategies and attitude towards the subject.

\section{Conclusion and recommendations}

Both the quantitative and qualitative results implied that there were differences in how frequent non-STEM students used coping strategies in general chemistry. There were some coping strategies they used more often than others to address their learning difficulties in the said subject. Thus, it is recommended that students be oriented on how they may cope with varied degrees of stress they encounter in general chemistry. Coping strategies such as accepting responsibility, positive reappraisal and planful problem solving can be incorporated in the orientation as a means of motivating the students to use these coping strategies. It is also recommended that schools conduct evaluation on students' experiences of stress to identify possible interventions to address these like conducting stress management training.

Ethical considerations: Informed consent was obtained from the participants of the study, while data supporting the reported results are available upon written request to the corresponding author.

\section{References}

Carver, C. S., \& Scheier, M. F. (1994). Situational coping and coping dispositions in a stressful transaction. Journal of Personality and Social Psychology, 66(1), 184-195. https://doi.org/10.1037/0022-3514.66.1.184

Carver, C. S., Scheier, M. F., \& Weintraub, J. K. (1989). Assessing coping strategies: A theoretically based approach. Journal of Personality and Social Psychology, 56(2), 267-283. https://doi.org/10.1037/0022-3514.56.2.267

Commission on Higher Education. (n.d.). CHED Memorandum Order no. 105, s. 2017. https://ched.gov.ph/wp-content/uploads/2018/01/CMO-No.-105-s.-2017-Policy-on-the-Admission-of-S enior-High-School-Graduates-to-the-Higher-Education-Institutions-Effective-Academic-Year-2018-201 9.pdf

Davis, G. E., \& Compas, B. E. (1986). Cognitive appraisal of major and daily stressful events during adolescence: A multidimensional scaling analysis. Journal of Youth and Adolescence, 15(5), 377-388. https://doi.org/10.1007/BF02143520

Dressler, W. W. (1991). Stress and adaptation in the context of culture: Depression in a southern black community. State University of New York Press.

Dyson, R., \& Renk, K. (2006). Freshmen adaptation to university life: Depressive symptoms, stress, and coping. Journal of Clinical Psychology, 62(10), 1231-1244. https://doi.org/10.1002/jclp.20295

Folkman, S., \& Lazarus, R. S. (1980). An analysis of coping in a middle-aged community sample. Journal of Health and Social Behavior, 21(3), 219-239. https://doi.org/10.2307/2136617

Folkman, S., \& Lazarus, R. S. (1985). If it changes it must be a process: Study of emotion and coping during three stages of a college examination. Journal of Personality and Social Psychology, 48(1), 150-170. https://doi.org/10.1037/0022-3514.48.1.150

Folkman, S., \& Lazarus, R. S. (1988). The relationship between coping and emotion: Implications for theory and 
Non-STEM students' learning difficulties and coping strategies in general chemistry under an engineering course research. Social Science \& Medicine, 26(3), 309-317. https://doi.org/10.1016/0277-9536(88)90395-4

Folkman, S., Lazarus, R. S., Gruen, R. J., \& DeLongis, A. (1986). Appraisal, coping, health status, and psychological symptoms. Journal of Personality and Social Psychology, 50(3), 571. https://doi.org/10.1037//0022-3514.50.3.571

Frydenberg, E., \& Lewis, R. (1993). Boys play sport and girls turn to others: Age, gender and ethnicity as determinants of coping. Journal of Adolescence, 16(3), 253-266. https://doi.org/10.1006/jado.1993.1024

Lawrence, J., Ashford, K., \& Dent, P. (2006). Gender differences in coping strategies of undergraduate students and their impact on self-esteem and attainment. Active Learning in Higher Education, 7(3), 273-281. https://doi.org/10.1177/1469787406069058

Lazarus, R. S. (1993). Coping theory and research: Past, present, and future. Psychosomatic Medicine, 55(3), 234-247. https://doi.org/10.1097/00006842-199305000-00002

Lazarus, R. S., \& Folkman, S. (1984). Stress, appraisal, and coping. Springer.

Lo, R. (2002). A longitudinal study of perceived level of stress, coping and self-esteem of undergraduate nursing students: An Australian case study. Journal of Advanced Nursing, 39(2), 119-126. https://doi.org/10.1046/j.1365-2648.2000.02251.x

McClure, J. W. (2007). International graduates' cross-cultural adjustment: Experiences, coping strategies, and suggested programmatic responses. Teaching in Higher Education, 12(2), 199-217. https://doi.org/10.1080/13562510701191976

Murray-Harvey, R., T. Slee, P., Lawson, M. J., Silins, H., Banfield, G., \& Russell, A. (2000). Under stress: The concerns and coping strategies of teacher education students. European Journal of Teacher Education, 23(1), 1935. https://doi.org/10.1080/713667267

Shaikh, B. T., Kahloon, A., Kazmi, M., Khalid, H., Nawaz, K., Khan, N., \& Khan, S. (2004). Students, stress and coping strategies: A case of Pakistani medical school. Education for Health, 17, 346-353. https://doi.org/10.1080/13576280400002585

Sirhan, G., (2000). A study of the effects of pre-learning with first year university chemistry students [Unpublished PhD Thesis]. University of Glasgow. https://core.ac.uk/download/pdf/293043006.pdf

Williams, K., \& McGillicuddy-De Lisi, A. (1999). Coping strategies in adolescents. Journal of Applied Developmental Psychology, 20(4), 537-549. https://doi.org/10.1016/S0193-3973(99)00025-8 